ISSN: 0212-0267

DOI: http://dx.doi.org/ro.I420I/hedu20I837303314

\title{
LA ESCUELA NORMAL DE MAESTROS DE BADAJOZ. SU PRIMER PERIODO HISTÓRICO (1844-I849)
}

\section{Normal School of primary teachers of Badajoz. First historical stage (I844-I849)}

\author{
Carmelo Real Apolo \\ Universidad de Extremadura \\ Correo-e: apolo@unex.es
}

Recepción: 23 de enero de 20I8. Envío a informantes: 29 de enero de 2018 Aceptación definitiva: 5 de marzo de 2018

Resumen: El desarrollo de las Escuelas Normales de maestros en España corre en paralelo a la redacción de la normativa que edifica nuestro sistema educativo. Con la fundación de un centro pedagógico de este tipo para formar a maestros en una provincia como Badajoz, eminentemente rural y analfabeta, se intentaría cumplir con el desiderátum liberal de elevar la felicidad y contribuir al bienestar material de todos los ciudadanos.

Del análisis del primer periodo histórico (1844-1849) de la Escuela Normal de Maestros de Badajoz resulta esta investigación que intenta ponderar su valor socioeducativo en un momento donde se requerían maestros que regentaran las escuelas de instrucción primaria de España y, en concreto, de las diseminadas por esta provincia extremeña. De la misma forma, se comprobará cómo dicha Escuela Normal quedó sujeta a las incertidumbres propias de toda institución que comienza su singladura académica.

Palabras claves: Escuela Normal, maestros, formación pedagógica, Badajoz, escuelas.

AвSTRACT: The development of the Normal Schools of the primary teachers in Spain took place at the same time of the drafting of the different laws which built our educational system. The foundation of such an academic centre to train the graduates to be teachers in the province of Badajoz, basically rural and illiterate, 
tried to fulfill the liberal aspiration of raising happiness and therefore contributed to the material well-being of all citizens.

This research arises as a result of the analysis of the first historical stage (1844I849) of the Normal Schools of primary teachers of Badajoz, which seeks to evaluate its social and educational value in a moment where teachers were needed to run the primary schools of Spain and, in particular, the schools which were scattered all over this province of the region of Extremadura. In the same way, it will verify how it had to face several uncertainties as an institution which started its academic journey.

KEY wORDs: Normal School, teachers, educational training, Badajoz, schools.

\section{Introducción y encuadre historiográfico}

1

l desarkollo de las Escuelas Normales en España corre en paralelo a la redacción de la normativa que edifica nuestro sistema educativo. Las primeras germinan con el abono que les propicia la Ley del marqués de Someruelos de I838, naciendo el 8 de marzo de 1839 la Escuela Normal Central de Madrid, de la que fue primer director don Pablo Montesino Cáceres. La presencia de estos centros en el resto de las provincias no se hará esperar y, a excepción de la Normal de Navarra, todas se fundarán después de que lo hiciera la dirigida por el afamado pedagogo zamorano. Así acontecerá en Badajoz, verificándose su inauguración en el año I844. Del análisis del primer periodo histórico de esta Escuela Normal resulta la presente investigación, encarnando el esfuerzo por ofrecer una aportación original y sustantiva de la trayectoria que recorre en estos años.

En la actualidad contamos con un nutrido número de investigaciones que tienen como objeto de estudio a estos centros; por ello, valoramos como un ejercicio de responsabilidad científica realizar una revisión bibliográfica del conjunto de publicaciones que han cristalizado en monografías, artículos y estudios de diverso calado y al que sumamos esta investigación. Señalando solo aquellos que limitan su análisis histórico al siglo xIx, y tomando como criterio su fecha de creación, se seguiría este orden para cada una de las provincias: Madrid (I839), Lérida (I84I), La Rioja (Logroño, I84I), Orense (I84I), Segovia (I84I), Soria (I84I), Teruel (I84I), Zamora (I84I), Albacete (I842), Cáceres (I842), Castellón (I842), Ciudad Real (I842), Córdoba (I842), Guadalajara (I842), Huesca (I842), Lugo (I842), Mallorca (Palma de Mallorca, I842), Salamanca (I842), Ávila (I843), Jaén (I843), Tarragona (I843), Valencia (I843), Alicante (I844), Asturias (Oviedo, I844), Badajoz (I844), Burgos (I844), Cantabria (Santander, I844), Gerona (I844), León (I844), Murcia (I844), Zaragoza (I844), A Coruña (I845 y Santiago de Compostela en I849), Barcelona (I845), Guipúzcoa (San Sebastián, I845), Pontevedra (I845), Sevilla (I845), Toledo (I845), Valladolid (I845), Almería (I846), Cuenca (I846), Granada (1846), Málaga (1846), Álava (Vitoria, I847), Tenerife (La Laguna, I849), Gran Canarias (Las Palmas, I853), Cádiz (I857), Huelva (I859), Palencia (I86I) y Vizcaya (Bilbao, I865). 
LA ESCUELA NORMAL DE MAESTROS DE BADAJOZ. SU PRIMER PERIODO HISTÓRICO (I844-I849)

CARMELO REAL APOLO

Esta producción historiográfica ofrece, ciertamente, un balance positivo pero muestra una distribución muy desigual, apareciendo zonas muy estudiadas, algunas con investigaciones parciales de notable importancia, y otras en las que la carencia de trabajos solventes es notable. Con todo es, sin duda, una fecunda producción científica que, como apunta De Gabriel, no agota la labor historiográfica de estos centros en nuestro país, si bien echamos de menos un estudio del conjunto que aglutine con coherencia y sentido todos los esfuerzos individuales y ofrezca una visión global que nos aproxime a una perspectiva comparativa de estas instituciones pedagógicas en el ámbito nacional.

\section{Los periodos históricos de la Escuela Normal de Maestros de Badajoz}

El marco temporal de cada uno de los periodos históricos de la Escuela Normal de Maestros de Badajoz queda delimitado por las distintas reformas que este centro experimentó a lo largo de la centuria decimonónica, advirtiéndose los altibajos en su trazado vital. Desde que abrió sus puertas el I8 de febrero de I844 como Escuela Normal y Seminario de Maestros, recorrió una andadura repleta de condicionantes legislativos y políticos. Así, a los pocos años de su aparición, el Real Decreto de i849 le atribuye la categoría de Escuela Normal Elemental (segundo periodo I849-I863) sujetándola, a su vez, a la autoridad del director del Instituto de Segunda Enseñanza provincial. Promocionará, en el año I863, a Normal Superior (tercer periodo I863-I868), quedando facultada para impartir el currículum de maestro de este grado y donde es ostensible el apoyo y el estímulo de la Diputación de Badajoz al contribuir económicamente a la consecución de este fin. Sin embargo, los nuevos tiempos traerán otros infortunios que hacen peligrar su presencia en el panorama educativo regional; sin duda, la agresión más grave vino por parte del artículo 35 de la Ley de Instrucción Primaria de 2 de junio de I868 que suprimió la Escuela Normal -suerte que compartiría con todas sus homólogas- aunque, afortunadamente, al poco tiempo fue repuesta por el Decreto de I4 de octubre de i868 (cuarto periodo i868-I900). Cada una de estas variaciones tiñó con ciertas peculiaridades cada periodo que superó esta institución, analizando en este trabajo aquellas referidas al primero (I844-I849).

\section{I. Breves notas sobre el proyecto de creación de una Escuela Normal de Maestros en la provincia de Badajoz}

La actuación de la Diputación de Badajoz en la preparación de un proyecto de Escuela Normal para esta provincia fue primordial. Más limitado fue, sin embargo, el apoyo que dispensó la Real Sociedad Económica de Amigos del País. Los trámites para establecer una Normal de Maestros en Badajoz se iniciaron en I837, pero estas primeras gestiones no culminaron con éxito. En 1838 se retomaron de forma más decisiva, fue entonces cuando la Comisión Provincial de Instrucción 
Primaria de Badajoz -no olvidemos que entre sus miembros se encontraba el jefe político y algunos diputados provinciales- apremió a la mencionada Diputación para que dispusiese de lo necesario para la fundación de un centro docente de este tipo en esta ciudad extremeña, lo que se evidencia en ese año cuando asume los gastos del sustento de dos becados en la proyectada Escuela Normal Central.

Posteriormente, el ministro del Interior, A. Hompanera de Cos, a través de la Circular de 29 de enero de i839, informa a la nación de que la Central de Maestros iniciará, por fin, su actividad académica el 8 de marzo de ese año; por lo tanto, para esas fechas deben ingresar en ese centro los alumnos seleccionados por cada provincia. Los aspirantes que presentaron solicitudes por parte de Badajoz para optar a estas plazas fueron: Antonio Álvarez Cienfuego, Joaquín Ramón Márquez, Francisco Rodríguez del Castillo, Alonso Soto, Juan Rebollo y Francisco Sánchez Rocha; de entre los cuales resultaron elegidos Francisco Rodríguez del Castillo y Joaquín Ramón Márquez.

No obstante, mientras la estancia de Francisco Rodríguez del Castillo en la Central será provechosa y quedará acreditado para la dirección de Escuelas Normales al superar los dos cursos reglamentarios con la calificación de «notablemente aprovechado» en los exámenes, la actitud de Joaquín Ramón Márquez -así como la de otros compañeros de estudios- no será la esperada, desinteresándose del compromiso que exige esta formación y, «olvidando los motivos de gratitud que debían estimularlos, han desmerecido por su reprensible conducta continuar disfrutando la pensión que en medio de tantas estrecheces satisfacen puntualmente las provincias» y con el fin de que «su ejemplo no contamine a los demás» se decide «excluir de la escuela normal a don Joaquín Ramón Márquez y a don Juan Fernández de la Peña, pensionados respectivamente por las provincias de Badajoz y Lugo», expulsión que se hace efectiva en diciembre de I839.

Al corriente de este episodio, la Diputación de Badajoz abrió un plazo para recibir nuevas solicitudes de interesados en cubrir la vacante del depuesto pensionado y, el 9 de marzo de 1840 , «se mandó poner una circular con toda urgencia, invitando a los sujetos que reunan las cualidades prevenidas por S.M. para alumnos de la Escuela Normal establecida en la Corte, que presenten sus solicitudes en el termino de quince días para proveer la vacante que tiene esta Provincia en dicho Establecimiento [...]», conviniendo que, si ninguno de los solicitantes reuniera los requisitos o no se recibiera ninguna petición, el nuevo pensionado fuera nombrado por el Gobierno. Sobre este hecho no hemos hallado datos que prueben la propuesta de cualquier otro candidato por parte de la provincia para realizar los estudios en la Central por lo que, finalmente, la elección de Joaquín López Patiño -natural de Madrid- debió correr a cargo de las autoridades estatales que lo designaron por Real Orden de 30 de junio de 1840 y que, a partir de octubre de I84I, cobraría los 300 reales de vellón que los presupuestos provinciales, según la legislación vigente, consignan para la compra de material.

Como se aguardaba, Francisco Rodríguez regresó a Badajoz una vez finalizados sus estudios en la Escuela Normal Central y, en i843, sobrevino la llegada del otro alumno normalista, Joaquín López Patiño. Con todo listo, tras 
LA ESCUELA NORMAL DE MAESTROS DE BADAJOZ. SU PRIMER PERIODO HISTÓRICO (I844-I849)

CARMELO REAL APOLO

cumplir con los trámites reglamentarios, el acto de inauguración de la Escuela Normal y Seminario de Maestros de Badajoz se celebró el día i8 de febrero de I844 a las ir de la mañana, leyendo un discurso don Tiburcio Zaragoza, gobernador de la Provincia, ante un nutrido grupo de autoridades y personalidades. Finalizada la jornada, el centro dio comienzo a su particular singladura histórica y académica.

\subsection{La Escuela Normal y Seminario de Maestros: análisis de su primer periodo (I844-I849)}

Con la siguiente noticia que remite don Tiburcio de Zaragoza, gobernador civil de la provincia, al Boletín Oficial de Instrucción Pública participa a la nación de la apertura de una Escuela Normal de Maestros en Badajoz:

Ministerio de la Gobernación de la Península. Gobierno político de la provincia de Badajoz. Excmo. Sr.: Según tuve el honor de indicar á V. E. en mi anterior comunicación de to del corriente, en el día de ayer se verificó la apertura de la escuela normal de esta provincia, instalada en el magnífico edificio que fue convento de Santa Catalina. La asistencia de las autoridades, corporaciones, sociedades literarias y científicas, cabildo, párrocos y demás personas ilustradas de esta ciudad, dieron á este acto un aspecto brillante; y en los semblantes de todos se notaba la mas pura alegría por ver satisfechos sus deseos con la inauguración de un establecimiento que no solo ofrece grandes ventajas á la mejora de la instrucción primaria de esta ciudad, sino á la de toda la provincia; y yo me complazco en hacerlo presente á V. E., asegurándole que no perdonaré medio de cuantos estén á mi alcance para que la educación pública, base de la civilización y la ventura de las naciones cultas, logre en esta provincia el impulso y mejora que el Gobierno tiene tan recomendado, y que mi corazón ansia por deber y reconocimiento. Dios guarde á V. E. muchos años.

Se esperaba que a la Escuela Normal y Seminario de Maestros acudiesen aspirantes venidos de todas las zonas de la provincia a recibir la «norma» a la que debían ajustarse para ser docentes y cumplir con un destino «que requiere particular preparación, una especie de noviciado para instruirse, para probar sus disposiciones y formar su vocación con el profundo conocimiento de los deberes que impone» y pese a su primera denominación como «Seminario de Maestros», no hallamos pruebas documentales que apoyen que los alumnos residieron en este centro en régimen de internado, quizás porque nunca llegó a establecerse por las limitaciones espaciales que imponía el edificio, o porque la legislación no precisaba su obligación. A mantener esta afirmación nos ayuda la clasificación de los alumnos en los exámenes anuales del curso 1845-1846 donde se recoge que todos los alumnos son externos, aspecto que reafirma nuestras pesquisas invalidando cualquier conjetura de que esta Normal dispusiese de un internado, careciendo de valor esta designación como seminario. 
El bisoño centro quedó -junto a la Escuela Práctica, producto de la fusión de las 2 escuelas pías de la ciudad-asentado en una parte de la planta baja del antiguo convento de Santa Catalina, ocupando la otra la Real Sociedad Económica de Amigos del País. En los aspectos organizativos, administrativos y pedagógicos respondió a lo que dictaba el Reglamento Orgánico para las Escuelas Normales de I843, documento que rechaza todo lujo en estos locales al estar dirigidos a personas «que han pasar su vida en condición oscura y honrada medianía».

No hemos podido hallar el Reglamento Interior de esta Normal, aunque sabemos que se compuso estando ya en funcionamiento y que se envió a la Comisión Superior de Instrucción Primaria para su aprobación antes de octubre de I844, sujetándose a él la organización de las asignaturas y los programas según

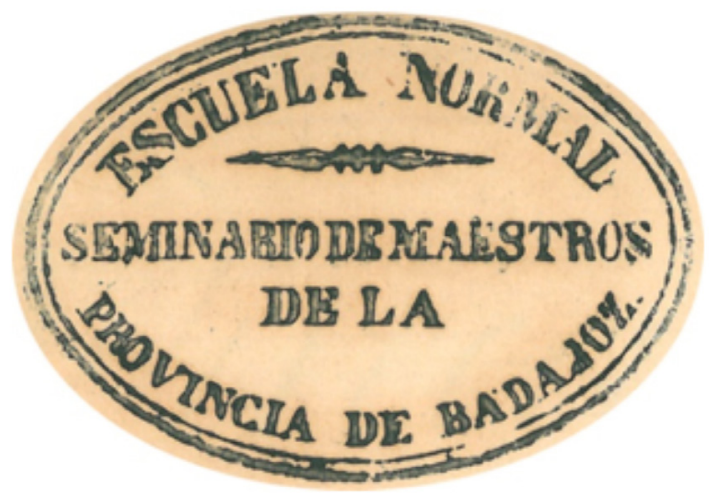

Sello de la Escuela Normal de Badajoz (de su primer periodo). nos verifica la documentación consultada para los cursos I844I845 $5^{\mathrm{I}}$ y $847-\mathrm{I} 848^{2}$, o la realización de los exámenes del año I $846^{3}$. Un reglamento que no quedó indemne a las reformas que se implantaron a lo largo del siglo, modificándose para acomodarse a las orientaciones originadas por el Real Decreto de I $849^{4}$.

Los inicios de esta Normal fueron muy modestos, desarrollando «una vida laboriosa y sencilla»s en todos los aspectos, quedando su infraestructura académica limitada a una cátedra para la enseñanza de todos los alumnos y a la Escuela Práctica, ubicada en el espacio que antes ocupó la iglesia del convento6. Sus restringidos recursos materiales eran los que, en su día, pertenecieron a las escuelas pías que sirvieron de base para establecer la Escuela Normal.

Ahenba, Programa de enseñanzas que se dan en la Escuela Normal-Seminario de Maestros de la Provincia de Badajoz ( 1844 y I845), documento fechado el 2 de octubre de 1844.

2 ahenba, Programa de las enseñanzas que explican en este Seminario de Maestros, concerniente al año escolar de 1847 a 1848 , con expresión de los nombres de los catedráticos que desempeñan aquellas y número de lecciones que se proponen dar semanalmente.

Para los que se elabora un programa donde se incluye de forma íntegra el título i4 de este Reglamento Interior y que trata de los exámenes. AHENBa, Observaciones al nuevo arreglo de exámenes, documento fechado el 20 de noviembre de 1846.

4 «A fin de reformar el Reglamento Interior de la Escuela, espero me lo remita V. S. [al director del Instituto] a la mayor brevedad, sin perjuicio de que a su tiempo sea examinado en Junta que al efecto se celebrará con asistencia de V. S. [director de la Escuela Normal] y del Regente de la escuela práctica». AHENBA, Expediente de arreglo de enseñanzas, programas y atribuciones de los Inspectores, n. ${ }^{\circ}$ 6. Año I 849 , Minuta fechada el 8 de octubre de 1851.

Gil de ZÁrate, A.: De la instrucción pública en España, p. 28I.

6 AHenda, Memoria que comprende la historia de referida escuela desde su creación hasta el presente, escrita por don Diego del Barco y Pérez. 
El cuadro docente en estos primeros años estuvo compuesto por Francisco Rodríguez del Castillo ${ }^{7}$-primer director-, Joaquín López Patiño ${ }^{8}$-como vicedirector-, Juan Antonio Rodríguez Hernández ${ }^{9}$ - profesor de Religión y Moral-y, como regente, Prudencio Fernández ${ }^{10}$. El inspector del centro fue José María Losada, miembro, a su vez, de la Comisión Provincial de Instrucción Primaria y que, tras su fallecimiento, ocurrido en agosto de I845, será sustituido por Nicolás Coronado ${ }^{\text {II }}$, nombrado inspector en propiedad en noviembre de $1845^{\mathrm{I2}}$.

Su perfil profesional presenta más sombras que luces. Su fatídica praxis como maestro en una de las escuelas pías de niños de Badajoz para la cual fue nombrado forzó a que, en agosto de I842, la Comisión Superior de Instrucción Pública lo alejara de la docencia, iniciando así una serie de visitas de inspección que lo llevaría a distintas localidades pacenses. Pese a todo, con 23 años se convirtió en el primer director (y primer maestro) de la Escuela Normal instalada en esta ciudad. Se trasladó a Salamanca en el verano de i849 para ocupar la dirección de la Escuela Normal Superior de Maestros de ese distrito universitario (Francisco Rodríguez del Castillo firma en el libro de exámenes -que abarca las fechas de 25 de septiembre de 1849 al 23 de septiembre de i866- como director de la de Salamanca desde el 26 de septiembre de I849 al 30 de septiembre de I852 (pp. I06-I07), cargo que ejercerá desde I849 a I852 [HERNÁNDEZ DíAz, J. M.a: «El sistema educativo liberal y la formación de maestros. Origen y primer desarrollo de la Escuela Normal de Salamanca (I842-I868)», Studia Historica, Iv, 4 (1986), p. 25]. Cuando abandona esta ciudad, se ocupó, de forma interina, de la dirección de la salmantina don Cesáreo Antolín Viñé y será el secretario don Cándido Sánchez de Bustamante (que antes había sido director de la Normal de Cáceres como pensionado por esta provincia). Archivo Histórico de la Universidad de Salamanca (en adelante, AHUSAL), Libro de exámenes (Escuela superior de Magisterio). Ref. AI/949/3). Desconocemos las causas que motivaron al señor Rodríguez del Castillo a abandonar este destino y de su traslado a Valencia, donde falleció de cólera en 1854 (AHus, leg. 1686. Nota de la historia de la creación..., doc. cit.).

8 Natural de Madrid, con 24 años, realizaría las funciones de segundo maestro en este centro. Finalizó los estudios de maestro elemental, superior y normal, completando su formación con el título de Agrimensor que logró en noviembre de 847 (AHus, leg. 5I4-06 [I]. Hoja de servicios de don Joaquín López Patiño). El traslado de Rodríguez del Castillo motivaría la emisión de la Real Orden del 26 de mayo de i849 que informaba de su nombramiento como nuevo director en Badajoz (la noticia de su nombramiento se recoge en el Boletín Oficial de la Provincia, i8 de junio de i849, n. ${ }^{\circ} 73$. Circular n. ${ }^{\circ}$ i86). Aunque don Joaquín López no tomó posesión de este cargo hasta el 30 de julio de ese año, ocupándose de la dirección por casi cuatro décadas (AHUs, leg. 5I4-06 [I]. Hoja de servicios de don Joaquín López Patiño).

9 Canónigo doctoral. Profesor de Religión y Moral en la Escuela Normal y encargado de las mismas enseñanzas en el Instituto de Segunda Enseñanza de Badajoz. Nombrado para esta plaza desde la fundación de este centro para maestros hasta enero de i853, fecha en la que cesa al ser nombrado canónigo magistral de Badajoz. AHENBA, Expediente relativo al personal y catedráticos de dicha Escuela, n. ${ }^{\circ} 4$.

1o Sabemos que nació en Badajoz. En diciembre de I829 fue nombrado maestro de la escuela pública elemental de Alburquerque, aunque lo hizo sin el título correspondiente que no lo obtuvo hasta el 30 de julio de i830, presentándose para ello a la Comisión Provincial de Exámenes. Luego se trasladó a Badajoz para regentar una escuela privada que desempeñó desde octubre de 1832 a agosto de I836, año en que pasó a ocupar una escuela pía en esta misma ciudad, a la que accedió por la renuncia del que la ocupaba Ildefonso Bancalero. Tenía 39 años cuando, al fusionarse las dos escuelas pías en la Escuela Práctica, fue propuesto como regente el ro de febrero de i844. Abandonaría estas responsabilidades en junio de 1850 para dirigirse a Fuente de Cantos (Badajoz) para hacerse cargo de una de sus escuelas (AHUs, leg. I686. Nota de la historia de la creación..., doc. cit.). Tras su cese, le seguirá en la regencia de la Escuela Práctica don Diego del Barco.

" Ahenba, Escrito de la Comisión Provincial de Instrucción Pública al director de la Escuela Normal, fechado el 4 de agosto de i845.

${ }_{12}$ ahenba, Escrito de la Comisión Provincial de Instrucción Pública al director de la Escuela Normal, fechado el 20 de noviembre de i845. 
El periodo de matrícula se publicó en el Boletín Oficial provincial, abriéndose el plazo el I8 de febrero de I844-mismo día de su inauguración-con el fin de iniciar las clases el is de marzo. Los interesados dirigirán las solicitudes, que irán llegando con cuentagotas, a la Comisión Provincial ${ }^{13}$ obligando a aplazar la actividad de la Escuela Normal hasta primeros de septiembre de i844, fecha de inicio que fijaba el artículo 54 del Reglamento Orgánico de i843, que también marcaba el término del curso para el i de julio. No obstante, hasta septiembre, al centro han llegado, en tiempo y forma, solo 4 solicitudes. Ante esta realidad, don Tiburcio de Zaragoza, como presidente de la Comisión Provincial de Instrucción Primaria, ampliará el plazo de matrícula hasta el 31 de octubre de i844 "para que las corporaciones municipales que deben remitir alumnos pensionados, no dejen de hacerlo en la creencia de ser pasada la época, ni tampoco los particulares que lo intenten $»^{14}$. Esta circunstancia provocará que en la Escuela Normal se reciban nuevas solicitudes una vez iniciado el curso, demorándose algunas de ellas en exceso $^{15}$, incidencias que, recapitulando, ocasionaron: (I) la inactividad de la Escuela Normal durante sus primeros meses por carencia de asistentes -el centro se inauguró el i8 de febrero, casi a mitad de curso-, (2) pese a que el plazo de matrícula se abrió el mismo día de su apertura con la intención de comenzar su misión docente el Is de marzo ${ }^{16}$, no lo podrá hacer hasta el I de septiembre de I $844^{17}$ por la causa apuntada y (3), por último, la falta de solicitudes llegada esa fecha también forzó a que, empezado el curso I844-1845, se admitieran nuevas instancias de alumnos que irán ingresando de forma escalonada.

En total serán is matriculados que, como hemos expuesto, se fueron incorporando paulatinamente al centro, un aspecto que se intentará corregir en su segundo año de funcionamiento recomendando el director que se defina un periodo de matrícula «como se hace en los demás establecimientos públicos [...] pasado el cual nadie pueda admitirse a cursar» ${ }^{18}$.

${ }_{13}$ Boletín Oficial de Badajoz, I2 de febrero de I844, n. ${ }^{\circ}$ 19, p. 8. Y también AHENBa, Datos históricos de la creación de referido establecimiento ordenados...

${ }^{14}$ Boletin Oficial de Badajoz, I4 de octubre de I844, n. ${ }^{\circ}$ I24.

is El número de alumnos que se alcanza al final no resulta muy boyante, sumando is la matrícula total: 7 inscritos en la enseñanza superior y 7 en la enseñanza elemental, más otro que es «no aspirante» (Ahenba, Datos históricos de la creación de referido establecimiento ordenados..., doc. cit. y, también: AHus, leg. I686. Nota de la historia de la creación..., doc. cit.). Sin embargo, por los datos contenidos en el libro de registro de matrícula, en este curso se incorporaron otros alumnos como: Francisco Gil, Francisco Ortiz López, Pedro Alvarado, Elías González, José Otero, José María Salcedo y Bernardino de la Torre, llegando la matrícula a ascender hasta los 22 alumnos, no obstante, tenemos que reducir esta cifra a 20 por la baja de Francisco Gil (de este alumno se conserva documentación en el AHENBA que confirma su interés por ingresar en el centro) y de Bernardino de la Torre, que no llegaron a presentarse en la convocatoria de los exámenes parciales ni generales de ese año (AHENBa, Libro de matrícula de alumnos del Seminario de Maestros [1844-I864]), lo que nos hace dudar sobre su incorporación efectiva al centro.

${ }^{16}$ Boletín Oficial de Badajoz, I2 de febrero de I844, n. ${ }^{\circ}$ I9, p. 8. Y también AHENBa, Datos históricos de la creación de referido establecimiento ordenados, doc. cit.

${ }^{17}$ Boletin Oficial de Badajoz, 30 de julio de 1845 , n. ${ }^{\circ} 90$.

18 AHENBA, Informe presentado a la Comisión al finalizar el curso de 1845 a 1846. 
LA ESCUELA NORMAL DE MAESTROS DE BADAJOZ. SU PRIMER PERIODO HISTÓRICO (I844-I849)

CARMELO REAL APOLO

TABla I. Grupo de alumnos del año académico I844-1845

\begin{tabular}{|c|c|c|c|}
\hline & NOMBRE y APELLIDOS & LOCALIDAD & FECHA DE ADMISIÓN \\
\hline \multirow{7}{*}{$\begin{array}{c}\text { ENSEÑANZA } \\
\text { SUPERIOR }\end{array}$} & José Cano Sánchez ${ }^{19}$ & Campanario & I5 de marzo de I844 \\
\hline & Fernando Beistegui & Barcarrota & I5 de marzo de I844 \\
\hline & Ventura Rodríguez & Badajoz & I4 de octubre de I844 \\
\hline & Juan Cerezano & Valladolid & 30 de octubre de I 844 \\
\hline & Pedro León Rey & Paredes de Navas (Palencia) & I de diciembre de I844 \\
\hline & José de las Heras ${ }^{20}$ & Llerena & 8 de enero de 1845 \\
\hline & Pío de la Riva ${ }^{2 I}$ & Fontanar (Guadalajara) & 24 de marzo de I845 \\
\hline \multirow{7}{*}{$\begin{array}{l}\text { ENSEÑANZA } \\
\text { ELEMENTAL }\end{array}$} & José Rivera & - & I5 de marzo de I844 \\
\hline & Simeón Muñiz & Galaroza (Huelva) & 3 de octubre de I844 \\
\hline & Alonso Soto & - & 3 de octubre de I844 \\
\hline & Manuel A. Sánchez & - & I4 de octubre de I844 \\
\hline & Nicolás Gutiérrez & - & I4 de octubre de I844 \\
\hline & Antonio Pérez Cano & Talarrubias & Io de noviembre de I844 \\
\hline & Antonio J. Ramírez & - & 2I de abril de I845 \\
\hline No aspirante & Ángel Coronado & Almendralejo & 24 de marzo de I844 \\
\hline
\end{tabular}

Para los siguientes cursos comprobaremos que esta Escuela Normal y Seminario de Maestros se llena con otros aspirantes que pensionan los diferentes municipios de la provincia, lo que favorecerá el mantener un grupo suficiente para cada uno de los años académicos que componen este primer periodo.

El plan de estudios ${ }^{22}$ que cursaron todos estos alumnos responde al establecido por el artículo 5 del Reglamento Orgánico de I843, un programa parco que centraliza toda su atención en dispensar los rudimentos básicos culturales y las destrezas fundamentales docentes ${ }^{23}$. Si bien propone una división sobre la utilidad de las disciplinas, que se cursarán en dos años (art. 7), no precisa un fraccionamiento de las materias para cada uno de ellos -ni cuáles serán las conducentes al grado elemental o al superior- y que la Escuela Normal de Badajoz, con el apoyo del Reglamento interno, decide resolver así para el primer curso de I844-I845 $5^{24}$ :

19 En I858, cuando el inspector provincial visita los pueblos del Partido Judicial de Villanueva de la Serena, descubrimos que es el maestro de la escuela superior de niños de esta localidad. CorTés CORTÉs, F.: Instrucción primaria e inspección de...

${ }_{20}$ Transcurridos catorce años, lo encontraremos en una escuela de este municipio cosechando buenos resultados y siendo felicitado por el inspector provincial. CORTÉs CoRTÉs, F.: Instrucción primaria e inspección de..., op. cit., p. 219.

${ }^{21}$ Años después ocupará una plaza de maestro en la localidad de Almendralejo. Cortés CorTÉs, F.: Instrucción primaria e inspección de..., op. cit., p. 202.

${ }_{22}$ GÓmez Rodríguez de CASTRO, F.: «El currículo de la formación del maestro (El momento histórico de la creación de las Normales en España) (1843-1857)", Historia de la Educación, 5 (1986), pp. 159-176.

${ }_{23}$ Sobre esta cuestión puede consultarse: Melcón Beltrán, J.: La formación del profesorado en España, Madrid, MEC, I992, p. I32; y, para Badajoz, se refiere a este aspecto concreto: SÁNCHEZ Pascua, F.: «Orígenes y primeros años de la Escuela Normal de Badajoz», Campo Abierto. Número monográfico de los I5o años de la Escuela de Magisterio en Badajoz (1994), pp. 43-44.

${ }_{24}$ Ahenba, Programa de enseñanzas que se dan en la Escuela Normal-Seminario de Maestros de la Provincia de Badajoz (I844 y I845). Fechado el 2 de octubre de I844. 
Tabla II. Organización curricular en la Escuela Normal de Badajoz (curso I844-1845)

\begin{tabular}{|c|c|}
\hline Primer año & Segundo año \\
\hline Religión y Moral & \multirow{3}{*}{$\begin{array}{l}\text { Se repiten las mismas pero no con igual nú- } \\
\text { mero de lecciones, aderezándose el programa } \\
\text { curricular con las materias de: Sistemas y } \\
\text { Métodos de Enseñanza }\end{array}$} \\
\hline Gramática Castellana & \\
\hline Educación & \\
\hline Caligrafía teórica y práctica & \multirow{4}{*}{$\begin{array}{c}\text { Historia Política } \\
\text { Dibujo lineal } \\
\text { Nociones de Química y Zoología }\end{array}$} \\
\hline Aritmética & \\
\hline Geometría & \\
\hline Geografía & \\
\hline $\begin{array}{l}\text { Las dos primeras partes de Historia Natural } \\
\text { (Mineralogía y Botánica) }\end{array}$ & \\
\hline
\end{tabular}

De este trazado curricular advertimos que no se recogen algunas asignaturas, apreciándose ciertas diferencias con respecto a la propuesta oficial. Algunas de ellas pueden entenderse como secuelas del artículo 6 del citado reglamento que permite suprimir, por falta de fondos o recursos, la materias más prescindibles y que pueden explicar estas alteraciones. Despojado de aquellas asignaturas que se consideran «de adorno», el currículum que se imparte es ralo y concentrado en aquellas disciplinas que trabajan las destrezas básicas ${ }^{25}$, desvirtuándolo hasta convertirlo en un programa académico más propio de una escuela de instrucción primaria superior que de un centro de formación de maestros ${ }^{26}$.

En los últimos años de la década se van torciendo las cosas para estas instituciones y se las somete a juicio. Así, el Real Decreto de i 847 requirió a los jefes políticos de provincias que informaran sobre su necesidad, allanando el camino para «reducir las escuelas normales seminarios de maestros de instrucción primaria, a las que sean puramente precisas, y estén mejor situadas para las necesidades de la enseñanza» (art. 55) ${ }^{27}$. Quienes estaban a favor de su supresión argumentaban que «además de ser gravosas a los pueblos, estaban desacreditadas por sus escasos resultados, y que su destrucción sería en todas partes mirada como un beneficio, descargando a las provincias de un gasto inútil, cuando pesaban sobre ellas otras muchas atenciones de mayor importancia ${ }^{28}$-mismos motivos que volveremos a encontrar para justificar el cierre de estos centros en I868 y 190I ${ }^{29}$. Poco después,

${ }_{25}$ Para las que se elaboran textos pedagógicos aprobados por la administración: Soler BALADA, M. A.: «Textos pedagógicos aprobados para su utilización en las Escuelas Normales desde su creación hasta 1868», Historia de la Educación, 2 (1983), pp. 87-95.

${ }^{26}$ La documentación consultada para los siguientes años académicos nos permite demostrar que este centro se esfuerza por ajustarse a lo reglamentado en I843 y, para el curso I846-I847, quedan establecidas las enseñanzas de todos los cursos correspondientes al grado elemental y superior.

${ }_{27}$ Real Decreto de 23 de septiembre de 1847 para la dotación de los maestros de instrucción primaria, y dando nuevo impulso a esta. Colección de Reales decretos, órdenes y reglamentos relativos a la instrucción primaria, elemental y superior desde la publicación de la Ley de 21 de julio de I838, Madrid, Imprenta de la V. de Perinat y compañía, I850, p. 78.

${ }_{28}$ Gil de Zárate, Antonio: De la Instrucción Pública... op. cit., p. 275.

29 Guzmán, M. de: Vida y muerte de las Escuelas Normales, Barcelona, PPU, 1986, pp. 52-53. 
LA ESCUELA NORMAL DE MAESTROS DE BADAJOZ. SU PRIMER PERIODO HISTÓRICO (I844-I849)

CARMELO REAL APOLO

una nueva amenaza viene por parte de las circulares de 3 de marzo y 20 de agosto de I848 que, dirigidas a las mismas autoridades provinciales que el anterior Real Decreto, facilitan que se supriman ${ }^{30}$.

La Normal de Badajoz supera las reticencias de aquellos que quieren prescindir de ella en 1847 , pero no podrá sortear el gran impacto que conlleva la enmienda a la totalidad que supuso el Real Decreto de i849 que reduce a 32 el número de Escuelas Normales en España y establece la división entre elementales y superiores $^{31}$. Tras esta reforma el centro pacense continuaría su funcionamiento pero ya como Escuela Normal de grado elemental.

Sin esperar a que los cambios que provoca esta normativa surtan efecto, el señor Rodríguez del Castillo remite un oficio a su homólogo del Instituto comunicándole su cese en la Normal pacense para pasar a ocupar, a partir de I de septiembre de 1849 , la plaza de director de la Escuela Normal Superior de Salamanca. La vacante que deja será asignada a don Joaquín López Patiño ${ }^{32}$ que, desde entonces, desarrollará una encomiable labor que condujo a este centro por los caminos más atinados en función, claro está, de lo tumultuoso que se presentó algunas veces su recorrido por el siglo XIX.

\section{Ideas finales}

Con la fundación en I844 de una Escuela Normal para formar a maestros de instrucción primaria en una provincia eminentemente rural y analfabeta, marcada por la ausencia social en la demanda de cultura, se intentaría cumplir con el desiderátum liberal de elevar la felicidad y contribuir al bienestar material de todos los ciudadanos. En su fase prístina, este centro estuvo sujeto a las incertidumbres propias de toda institución que empieza y, ya inaugurada, trascurrieron varios meses hasta su efectiva puesta en funcionamiento, un retraso que no respondió a cuestiones económicas, como justificaron muchas diputaciones provinciales (por ejemplo: Sevilla $a^{33}$ o Almería ${ }^{34}$ ), sino que la demora se debió a la ausencia de alumnos con la que llenar sus aulas.

Cabe destacar el empeño de la Diputación de Badajoz por fundar una Escuela Normal, siendo la segunda en establecerse en el distrito universitario de Sevilla. Distrito que se compone con las provincias de Sevilla (I845)-como centro académico-administrativo-, Cádiz (1857), Córdoba (1842), Badajoz, Huelva (1859) y las Islas Canarias (Tenerife, I849 y Gran Canaria, 1853) y todas ellas, a excepción de

- Colección de Reales decretos, órdenes y reglamentos..., op. cit., p. 25 I.

31 Gil de Zárate, A.: De la Instrucción Pública..., op. cit., p. 276.

32 AHENBa, Expediente relativo a la Hacienda y contabilidad de esta Escuela, n. ${ }^{\circ}$ 2, I849, Minuta fechada el 29 de agosto de I849.

33 Ávila Fernández, A.: Historia de la Escuela Normal de Maestros de Sevilla en la segunda mitad del siglo XIX, Sevilla, Alfar, I986, 2 vols., p. 503.

34 Ballarín Domingo, P.: La Escuela Normal de Maestros de Almería en el siglo XIX, Granada, Universidad de Granada, 1987, p. 242. 
Huelva, cuentan con una Normal de maestros antes de este trazado organizativo que establece la Ley Moyano.

El tiempo hará patente que estas instituciones vinieron a incrementar el número de maestros de escuelas de instrucción pública ${ }^{35} \mathrm{y}$, por supuesto, a mejorar la calidad educativa en cada una de las provincias en las que fueron instaladas, todas ellas con altas tasas de analfabetismo ${ }^{36}$.

Los años de este primer periodo de la Escuela Normal y Seminario de Maestros de Badajoz no fueron fáciles, teniendo que superar dificultades administrativas, económicas, materiales e imposiciones legales, abriéndose paso a través de un lodazal de disposiciones legislativas que no siempre la favorecieron.

Con algunas asignaturas que se imparten en estos centros, se intentó superar el pobre programa de estudios dirigido a los maestros limitado, la mayoría de las veces, a la enseñanza de la lectura, la escritura y el cálculo. Así, en el último curso analizado de esta Escuela Normal observamos cómo se logró completar en su totalidad la construcción curricular que quedó propuesta en el Reglamento de I843, aunque prevalecerán los conocimientos culturales muy por encima de los pedagógicos -siguiendo la filosofía educativa que marcaba el preámbulo del mencionado reglamento-, que quedaban circunscritos a los contenidos que encarnan las asignaturas de Educación y Sistemas y Métodos de Enseñanza ${ }^{37}$.

El final de nuestros análisis coincide con la recomposición institucional que implanta la reforma de I849 que altera el paso histórico de este centro, dando inicio a una nueva etapa clasificada como Escuela Normal Elemental, despojada ya del rótulo de seminario. Todas sus homónimas del distrito universitario, menos la de Sevilla, correrán la misma suerte, pero, aun así, esta Normal extremeña continuaría siendo una institución clave en el desarrollo pedagógico de la provincia.

35 Ávila Fernández, A.: «La formación de los maestros en España: Una deuda histórica», Historia de la Educación, 26 (2007), pp. 327-340.

${ }_{36}$ Niveles que perduran elevados durante toda la centuria, pero para obtener datos más precisos sobre las tasas de analfabetismo en estas provincias a finales de siglo remito al estudio de: Vilanova Ribas, M. y Moreno Juliá, X.: Atlas de la evolución del analfabetismo en España de I887 a I98I, Madrid, Centro de Publicaciones del Ministerio de Educación y Ciencia, I992. También puede consultarse: GUEREÑA, J. L.: «La estadística escolar en el siglo XIX», Historia de la Educación, 7 (1988), pp. 137-I47.

37 Ávila Fernández, A.: Historia de la Escuela Normal de..., op. cit., tomo iI, p. 522. 